\title{
A Study on Chinese Teaching Strategies for Foreign Academic Students in Local Agricultural University
}

\author{
Song Shuo ${ }^{1, a}$, Wei Xiaoming ${ }^{2, b}$ Sana Khulood Siddiquii,c \\ ${ }^{1}$ Jilin Agricultural University, Changchun, Jilin, 130118 \\ ${ }^{2}$ Jilin Agricultural University, Changchun, Jilin, 130118 \\ ${ }^{3}$ Faculty of Education University of Sindh, Pakistan 710000 \\ asongshuoa304@sohu.com,b520089051@qq.com, csanakhulood@yahoo.com
}

Keywords: Local Agricultural University ; Foreign academic students; Chinese teaching strategies

\begin{abstract}
Teaching of Chinese language for foreign academic students in Local Agricultural University is the comprehensive need for talent's cultivation, cultural literacy promotion and internationalization development of higher agricultural education. Local Agricultural University is facing some problems such as marginalization, content convergence, simple teaching methods and administrative management of teachers. This paper aims to improve foreign academic student's scale and education quality in local Higher Agricultural Universities by deepening the understanding of Chinese teaching, strengthening the research of foreign academic student's needs, establishing the teaching system both inside and outside the classroom and improving the professional training of TCSL teachers.
\end{abstract}

\section{Introduction}

Foreign academic students become an important symbol for the internationalization level of colleges. With the accelerated internationalization process of higher education, higher agricultural colleges have attracted more and more international students to study in China. The number of foreign academic students attending international education has increased rapidly, and the proportion has steadily increased and become the main body of international students in China ${ }^{[1]}$. With the growing scale of foreign academic students, Chinese language, as a media of cultural exchange and knowledge dissemination plays a very important role in the field of personnel training. On June 6, 2017, Ministry of Education, Ministry of Foreign Affairs, and Ministry of Public Security jointly promulgated 'College acceptance and cultivation management approach of international students' which clearly pointed out that Chinese is the compulsory course of higher education and basic teaching language of college in international students teaching ${ }^{[2]}$. Under this new normal state, how to implement Chinese teaching according to the physical needs and learning characteristics of foreign students is an important problem that is urgently need to be solve.

\section{The significance of Chinese teaching for foreign academic students in Local Agricultural University}

\section{A. Chinese teaching is the basic guarantee for the training of foreign academic students}

When foreign academic students study in China, the first thing to overcome is communication and language barrier. Although, mostly the Local Agricultural Universities teach English teaching mode. The study and life of international students are still in Chinese cultural environment. If the international students do not understand Chinese, they would meet difficulties in normal routine life, academic experiments,(thesis, seminar) defense, internship and many other links needs to use Chinese communication. Therefore, Chinese teaching is a necessary link for foreign academic students to entirely understand the learning and living environment, better study of appropriate professional courses, adapting to the experiments and internship environment. It is the basic 
guarantee for the cultivation of international students.

\section{B. Chinese teaching is an important way to improve the cultural quality of students studying abroad}

Learning Chinese involves the master of cultural knowledge contained in Chinese. It is now understood that the ones who have more depth of Chinese cultural knowledge can more effectively understand and develop Chinese communicative competence. Most of the foreign academic students in local colleges are from developing countries, they belongs to the different cultures and educational backgrounds, which cause cultural dissimilarity phenomenon during their studies. Lack of cultural understanding makes them unable to fit into normal learning life. Chinese learning is a long-term process that's why Foreign academic students (studying) not only learn the language but also understand excellent cultural connotation of Chinese from language learning. Further more they understand and learn how to treat different cultural differences correctly, so as to improve cultural ethics quality and develop the noble sentiments of understanding, friendship and feel affection for China.

\section{Chinese teaching is the practical need to promote the internationalization for Higher Agricultural Education}

The Internationalization for Higher Agricultural Education of China is still in its infancy, and the international community knows little about China's situation. Chinese teaching can provide an opportunity for international students to fully understand China's Higher Agricultural Education. With regard to foreign experience, some countries achieved internationalization of higher education through international courses and local language training. [3] Therefore it is necessary, to strengthen Chinese language teaching for foreign academic students in international education market mining and investment. After studying abroad, foreign academic students can play vital role to enhance the international understanding of China's Higher Agricultural Education through propaganda, and establish the communication in order to further promote the internationalization development of China's Agricultural colleges and universities that lay the foundation to attract more international students to study in China.

\section{The problems existing in Chinese teaching for foreign academic students in Local Agricultural University of china}

\section{A. Discipline status has not been confirmed and Chinese teaching is marginalized}

Chinese language is listed as a required course for foreign academic students of higher agricultural institutions, that's why as a non-academic language training course, it is difficult to find the corresponding academic status and name under the education system of agriculture-related subjects. Chinese teaching for foreign academic students in local higher agricultural universities is still regarded as "foreign affairs" and marginalized in a complicated situation. The majority of local agricultural institutions' teaching Chinese to foreign students is still under the overall management by foreign affairs departments, which seems having untrained teachers and having lack of professional teaching guidance. This lack of knowledge and management dislocation to some extent affects the enthusiasm of teachers and students learning initiative, limiting the effective (role)of Chinese language education function, and restricting the great potential of foreign academic student's education development in local higher agricultural institutions.

\section{B. Teaching content convergence cannot meet the diverse needs of students}

Foreign academic students Chinese teaching in local higher agricultural universities is developed from the earliest Chinese preparatory education. Although after several reforms, with the limit of 
teaching conditions, teachers, students range and other factors in foreign academics, student's in Chinese teaching are still organized and implemented as compare to Chinese preparatory education.Although learning and Chinese teaching efficiency is not high, at present, most of the local Agricultural and other universities have implemented this subject knowledge system centered teaching theory, emphasizing the inherent logic system of linguistic knowledge to organize the curriculum, which emphasizes on Chinese teaching knowledge with very little skills training and little concern about the needs of students and acceptance ability. Because of its complex content and long learning time, it cannot meet the academic needs of international students' professional studies and career development. Many international students cannot use Chinese for entire life communication and professional exchanges after learning Chinese.

\section{Teaching methods are single and students learning interest is not high}

Local high agricultural colleges and universities mostly use sub-skills teaching mode, and teaching methods are of spoon-type teaching. This way of teaching method results in lack of understanding the characteristics of students, therefore it is difficult to mobilize the enthusiasm and initiative for foreign academic students to learn Chinese. Most of international students in local higher education universities are from non-Chinese cultural circles, and they feel extreme difficulties in Chinese learning process. There is huge gap without professional skilled teachers which can enhance the interest in learning according to the characteristics of students and exclude students' psychological barriers is an important task of Chinese teaching.

\section{Administrative management of teachers and lack of theoretical research}

Generally TCSL teachers in local higher agricultural universities are generally non professional teachers employed by International Educational Exchange Institute. They mainly serve the needs of the development of international education in schools, so in addition to teach Chinese as a foreign language, they are also responsible for student education management and other administrative work. Most of these teachers are not teachers of foreign language proficiency, and there are some limitations in teaching Chinese as a foreign language. While, because of numerous administrative responsibilities, these teachers' teaching and research ability are relatively weak. Due to extra administrative burden they are weak in their research work and theory, which results the lack on the motivation in the development of Chinese teaching

\section{The main strategies of teaching Chinese as a foreign language in higher agricultural universities}

\section{A. Deepen the understanding of Chinese teaching for foreign academic students and clear the purpose of Chinese teaching as a foreign language}

Teaching is the most important way to achieve the purpose of education, especially for intellectual attainment. In educational system, teaching is the central and core part, It is like the backbone of whole teacher student learning process.

The educational tasks for foreign students are achieved mainly through the teaching of Chinese. At present, $80 \%$ of foreign academic student's scholarship in higher agricultural universities of China are based not only on Chinese knowledge teaching and Chinese communicative ability cultivation, but also the intelligence and physical strength development of foreign students and their understanding, friendliness and love for China.

\section{B. Strengthen the academic needs of research for foreign students and integrate teaching resources for Chinese as a foreign language}

American educator John Dewey point out that education is the life which (is to )enable students to 
master the knowledge of practical problems. Most of foreign academic students in higher agricultural universities are from Asian and African developing countries. Their language and cultural background are different, so their purpose and needs of Chinese learning are not the same. Only by understanding their learning motivational needs, learning strategies and deficiencies can be better associate with changing teaching methodologies according to their social needs and personal development so as to fully mobilize their learning initiative as well as enthusiasm to improve their Chinese language skills level and abilities.

\section{Establishing the external and internal teaching system to create a full language environment}

TCSL teaching for foreign academic students in higher agricultural universities is the process of adult Chinese learning. Therefore, Chinese teaching for them has a certain degree of complexity. Traditional language is teaching based, on inter-language in translation process tends to increase the difficulty of understanding. Teachers should make full use of the internal and external language environment to strengthen student's Chinese language communication practice in different context. Advanced multimedia teaching methods are used to improve student's intuitive understanding of knowledge and are conducive to the establishment of teacher's language and role models to enhance the culture edification for international students.

\section{Strengthen the professional training of Chinese teachers as a foreign language and improve teaching strategies}

The subjective attributes of Chinese as a foreign language have special requirements of teachers in terms of knowledge structure and ability quality. Chinese teachers should not only have deep knowledge of Chinese, but also master the basic skills of cross-cultural teaching as well as professional skills in English. Therefore, Chinese language teachers, especially non-disciplinary students, need to strengthen their business training so that they can familiarize themselves with the knowledge they need in this profession and master the principles and methods of Chinese teaching. Only by forming a good learning atmosphere, best teaching strategies, appropriate teaching methodologies and skills of Chinese teachers can achieve the desired teaching goals of proficiency in Chinese as a foreign language .

\section{Acknowledgments}

This work is supported by the "13th Five-year"Social Science Research Project of education Department of Jilin Province JJKH20170323SK.

\section{References}

[1] Song Shuo. The situation and thinking of higher agricultural college international students education [J]. Higher Agricultural Education. 2014 (4).

[2] Zhang Shuo. Three ministries: Chinese and Chinese profiles should be as a compulsory course for international students in higher education [N] People's Daily 2017-6-5 (10)

[3] Lai Binggen, Zhou Yi. Germany's experience and its enlightenment of higher education internationalization [J]. Education Exploration, 2009 (6). 